\title{
2,3,5-TRIPHENYL-2 $H$-TETRAZOLIUM CHLORIDE AS A REAGENT FOR THE DETERMINATION OF SUGAR MIXTURES BY A DIFFERENTIAL REACTION-RATE TECHNIQUE
}

\author{
Harry B. Mark, Jr, Lynn M. Backes and Danifl Pinkel* \\ Department of Chemistry, The University of Michigan \\ Ann Arbor, Michigan, U.S.A. \\ and \\ LoUIS J. PAPA \\ Organic Chemistry Division, Jackson Laboratories \\ E. J. Du Pont de Nemours and Co. \\ Deepwater, New Jersey, U.S.A.
}

(Received 3 July 1964. Accepted 10 September 1964)

\begin{abstract}
Summary-The rates of reaction of 2,3,5-triphenyl-2 $\mathrm{H}$-tetrazoliurn chloride with the more common hexoses (glucose, fructose, mannose, sorbose and galactose) and pentoses (xylose and ribose) have been studied. Under certain conditions, over a limited range of reaction, the extent of the reaction is directly proportional to the time of reaction (a "pseudo zero-order" reaction). Also, the rates of reaction of the sugars are quite different in most cases. Thus, the behaviour of this reagent is quite satisfactory for the determination of binary mixtures of most of the sugars tested, by a simple differential rate technique developed for "zero-order" competitive reactions. The rates of reaction of 2,3,5-triphenyl-2H-tetrazolium chloride with ascorbic acid, creatinine and glutathione, often found in blood serum, which interfere with most blood serum sugar analysis methods, have also been examined to determine if they would interfere with the determination. Glutathione and creatinine do not react with the reagent and do not interfere with the analysis of sugar mixtures. Ascorbic acid, however, reacts rapidly, and as little as $1-2 \%$ leads to error in the sugar-mixture determination.
\end{abstract}

\section{INTRODUCTION}

IN general, the analysis of sugar mixtures is carried out in two steps: the mixture is first separated by paper or column chromatography, and this is followed by a quantitative evaluation of the spots or fractions." Gas chromatographic techniques have also been employed, following methylation of the sugars. ${ }^{2-4}$ Methods for the in situ determination of sugar mixtures based on techniques employing differential reaction rates have also been reported. ${ }^{5-7}$ None of these differential reaction-rate methods are entirely satisfactory for rapid routine analysis, because of either laborious procedure or slow time-consuming reactions. The method of Siggia et al., ${ }^{5}$ based on the differential rates of dialysis of the sugars, although reported to be very accurate, and capable of determining three-component mixtures, is somewhat time-consuming, requiring 15-50 titrations during the course of an individual mixture determination. The two chemical reaction-rate methods, based on the differential rates of reaction of

- Participant in the University of Michigan Undergraduate Honors Research Programme. 
the sugars with anthrone, ${ }^{6}$ or with ammonium molybdate, ${ }^{7}$ are somewhat less laborious, requiring only two simple spectrophotometric measurements for each mixture analysis. However, both reagents have distinct disadvantages: in the anthrone method two measurements are made at two different temperatures, $25^{\circ}$ and $100^{\circ}$; and the ammonium molybdate method employs a very slow reaction ( $2 \mathrm{hr}$ reaction time at $\left.100^{\circ}\right)$.

The compound 2,3,5-triphenyl-2H-tetrazolium chloride (THTCl) reacts readily under mild conditions with reducing compounds, such as sugars, ${ }^{8}$ to form a red water-insoluble formazan; 9,10 the quantity of this is directly proportional to the concentration of the sugars. ${ }^{11}$ This red precipitate is readily dissolved on adding acid-pyridine to the solution, and this reagent also serves to stop the reaction. Therefore the amount of formazan formed at any time during the course of the reaction is readily measured spectrophotometrically. ${ }^{11}$ Mattson and Jensen ${ }^{11}$ also observed that fructose had a "seven-fold greater reducing power" (a faster rate of reaction) than glucose. It therefore appeared that THTCl might be a very suitable reagent for the analysis of sugar mixtures by a differential reaction-rate technique. This paper reports the results of the investigation of the reaction of this compound with sugar mixtures and its applicability as a reagent for their analysis.

\section{General procedure}

\section{EXPERIMENTAL}

The reaction solution is prepared by dissolving the sugar mixture in water to give a solution which is approximately $1-5 \mathrm{~m} / \mathrm{molar}$ in total sugar, a concentration range of sugar which gives convenient absorbance values on reaction (generally between 0.2 and 0.8 ). Two 10-ml samples of the sugar solution are then introduced into $50-\mathrm{ml}$ volumetric fiasks, placed in a thermostatted water bath at $25^{\circ} \pm 0.05$ and allowed to come to thermal equilibrium; $5.0 \mathrm{ml}$ of $1.00 \mathrm{M} \mathrm{NaOH}$ are then added to each flask, and the solution is mixed and allowed to stand for about $6 \mathrm{~min}$ to ensure thermal equilibrium. The reaction is started by the addition of $1.0 \mathrm{ml}$ of a freshly prepared $0.015 \mathrm{M}$ solution of THTCl. One of the sample solutions is allowed to react for $20 \mathrm{~min}$ and the other for $50 \mathrm{~min}$. The reactions of the two samples are stopped at the appropriate times by the addition of $15 \mathrm{ml}$ of a pyridine-conc. hydrochloric acid solution $(20: 3, \mathrm{v} / \mathrm{v})$. The addition of this reagent also dissolves the red formazan product of the reaction. The extent of the reaction at these two times is determined by measuring the absorbance of the resultant solutions at $490 \mathrm{~m} \mu$. A Beckman model DU spectrophotometer was employed in this study and the blank was a solution containing all the species, except the sugar, in the concentrations initially added to the sample solution.

The rates of reaction of the pure individual sugars were determined in the same manner. The extent of the reactions for the individual sugars were, however, measured over a large range of time intervals.

\section{Calculation of the composition of the mixtures}

In the reaction conditions described, the rates of formation, for all the sugars $A$ studied, of the red formazan product, $R$, in the reaction:

$$
A+\mathrm{THTCl} \rightarrow R
$$

were directly proportional, over a limited part of the initial portion of reaction, to the time of the reaction, as shown in Fig. 1. The amount of $R$ formed at any given time, $t$, during the course of the reaction, was directly proportional to the initial concentration of the sugar present (see Fig. 2). Thus, a very simple proportional relationship describes the concentration of the formazan product, as a function of time and initial concentration of sugar:

$$
[R]_{t}=k_{\Delta} t\left[S_{d}\right]_{0}
$$

where $[R]_{t}$ is the concentration of the product at any time, $t, k_{A}$ is the proportionality constant which can be considered to be a "pseudo zero-order" rate constant for the reaction of the sugar, $A$, and $\left[S_{A}\right]_{0}$ is the initial concentration of the sugar, $A$. Because the absorbance of the formazan is the measured parameter, and because the formazan obeys Beer's Law, the measured absorbance, $P_{b}$, at any time, 
$t$, is also directly proportional to $t$ and $\left[S_{A}\right]_{0}$; and at a fixed value of $t$ it is directly proportional to $\left[S_{A}\right]_{0}$ only:

$$
P_{t}=\varepsilon b k_{\Delta} t\left[S_{\Delta}\right]_{0}=K_{\Delta, t}\left[S_{\Delta}\right]_{0}
$$

where $\varepsilon$ and $b$ are the molar absorptivity of $R$ and the path length of light in the spectrophotometer cell, respectively; and $K_{\Delta, t}$ is the proportionality constant relating $P_{t}$ to $\left[S_{\Delta}\right]_{0}$ at any fixed value of $t$.

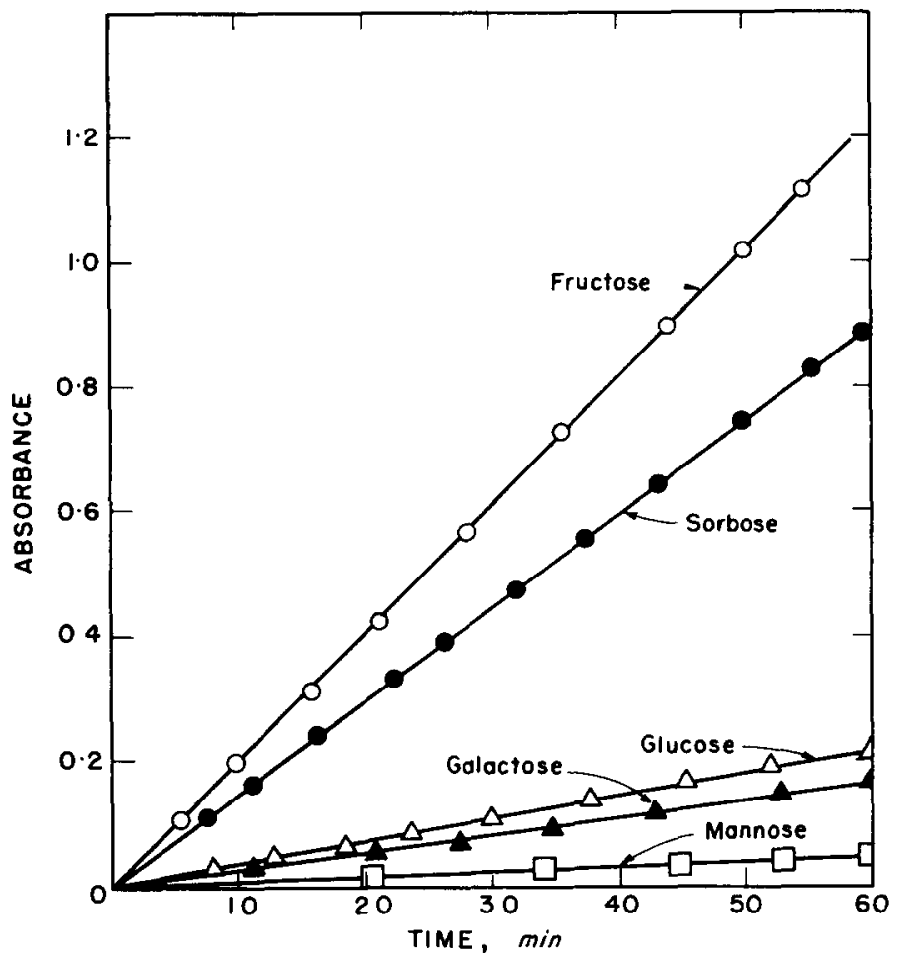

Fig. 1.-Reaction rate curves of five hexoses.

Concentration of hexose $=1 \times 10^{-8} \mathrm{M}$;

concentration of $\mathrm{THTCl}=0.94 \times 10^{-3} \mathrm{M}$;

temperature $=25^{\circ} \pm 0.05^{\circ}$.

If two sugars, $A$ and $B$, react simultaneously and competitively with $\mathrm{THTCl}$ to form the formazan products, but with different rate constants, $K_{A}$ and $K_{B}$ respectively:

and

$$
\begin{aligned}
& A+\mathrm{THTCl} \stackrel{k_{A}}{\longrightarrow} R \\
& B+\mathrm{THTCl} \stackrel{k_{B}}{\longrightarrow} R
\end{aligned}
$$

The total concentration of formazan, measured as an absorbance value, $P$, at two different times, $t$, and $t^{1}$, during the course of the reaction is given by:

and

$$
\begin{gathered}
P_{t}=K_{A, t}\left[S_{A}\right]_{0}+K_{B, t}\left[S_{B}\right]_{0} \\
P_{t}{ }^{1}=K_{A, t}{ }^{1}\left[S_{A}\right]_{0}+K_{B, t}{ }^{1}\left[S_{B}\right]_{0}
\end{gathered}
$$

Where $K_{A, t}$ is defined by equation (3), $K_{A, t}{ }^{1}$ is equal to $\varepsilon b k_{A} t^{1}$, and $K_{B, t}$ and $K_{B, t^{1}}$ are proportionality constants of the same form, except that they contain $k_{B}$ [the "pseudo zero-order rate constant" of the reaction of $B$; equation (5)] rather than $k_{\Delta}$. The values of these four $K$ constants in equations (6) and (7) are easily determined experimentally by measuring the values of $P$ obtained for the reactions of known initial concentrations of pure $A$ and $B$ at the two time intervals, $t$ and $t^{1}$ [see equation (3)]. The values of $\varepsilon, b, k_{A}$ and $k_{B}$ do not have to be known separately. 
With the values of the $K$ constants predetermined, the analysis of a two-component sugar mixture is then accomplished by simply measuring the absorbance, $P$, at the two times $t$ and $t^{1}$. These values can then be used with equations (6) and (7), which can be solved simultaneously to give $\left[S_{A}\right]_{0}$ and $\left[S_{B}\right]_{0}$. This type of calculation using proportional equations is the same as that employed for the analysis of mixtures undergoing first-order reactions ${ }^{12}$ and enzyme catalysed reactions. ${ }^{12}$ Only the form of the proportional equations is different in each case.

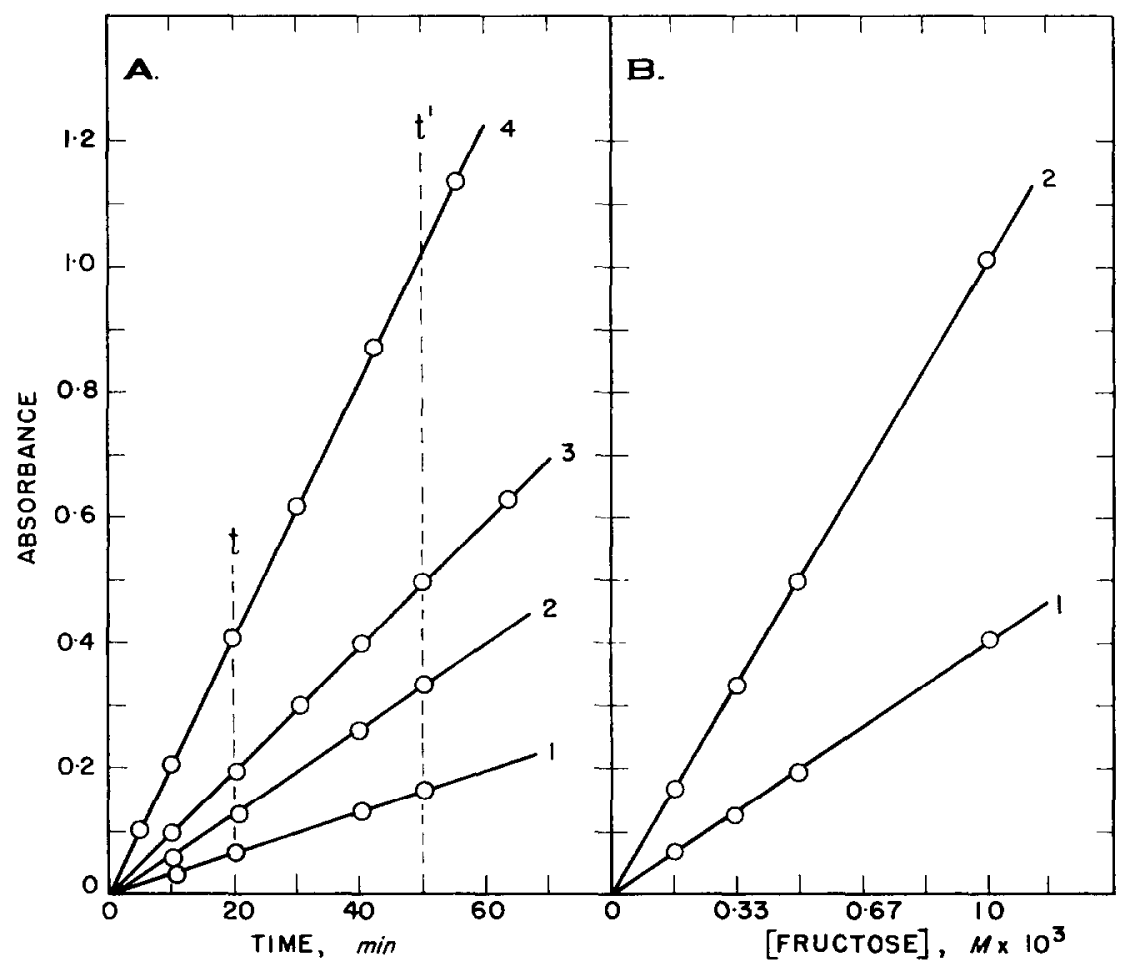

Fig. 2.-Effect of concentration of fructose on the rate of reaction.

Concentration of $\mathrm{THTCl}=0.94 \times 10^{-8} \mathrm{M}$; temperature $=25^{\circ} \pm 0.05^{\circ}$.

A: Curve 1. Concentration of fructose $=0.17 \times 10^{-3} \mathrm{M}$.

Curve 2. Concentration of fructose $=0.33 \times 10^{-3} M$.

Curve 3. Concentration of fructose $=0.50 \times 10^{-3} \mathrm{M}$.

Curve 4. Concentration of fructose $=1.00 \times 10^{-3} \mathrm{M}$.

B: Curve 1. Extent of reaction at time, $t=20 \mathrm{~min}$.

Curve 2. Extent of reaction at time, $t^{\prime}=50 \mathrm{~min}$.

\section{RESULTS AND DISCUSSION}

In order to determine the optimum conditions for the analysis of sugar mixtures using the THTCl reagent, the rates of reaction of the different hexoses were investigated over a range of sugar and reagent concentrations. The most reproducible rate values were obtained when the ratio of the total concentration of sugars to THTCl was approximately $1: 15$ to $1: 1$, i.e., second order conditions. Under these conditions the reaction at $25^{\circ}$ is quite slow. It can be seen in Fig. 3, that the reaction with the fastest reacting sugar, fructose, requires over $6 \mathrm{hr}$ to go to completion. This slow rate of reaction under these conditions makes this reagent unsuitable for the usual graphical second order differential rate methods, ${ }^{14-15}$ which require the reaction of the 
mixture to approach completion. Also, the rate results obtained for times greater than about $3 \mathrm{hr}$ were not very reproducible. This may possibly be either because the over-all reaction is quite complex (the linear behaviour of the initial rate also suggests this) or because the formazan product is somewhat unstable (as discussed below). However, because the rate values during the initial portion of the reaction (up to $2 \mathrm{hr}$ ) were quite reproducible, and the extent of the reaction was conveniently linear with respect to time during this period, the determination of sugar mixtures can easily be made as explained above. The one disadvantage in using merely the initial reaction rate values is that only a small per cent, $10-20 \%$, of the reaction has taken place. Thus.

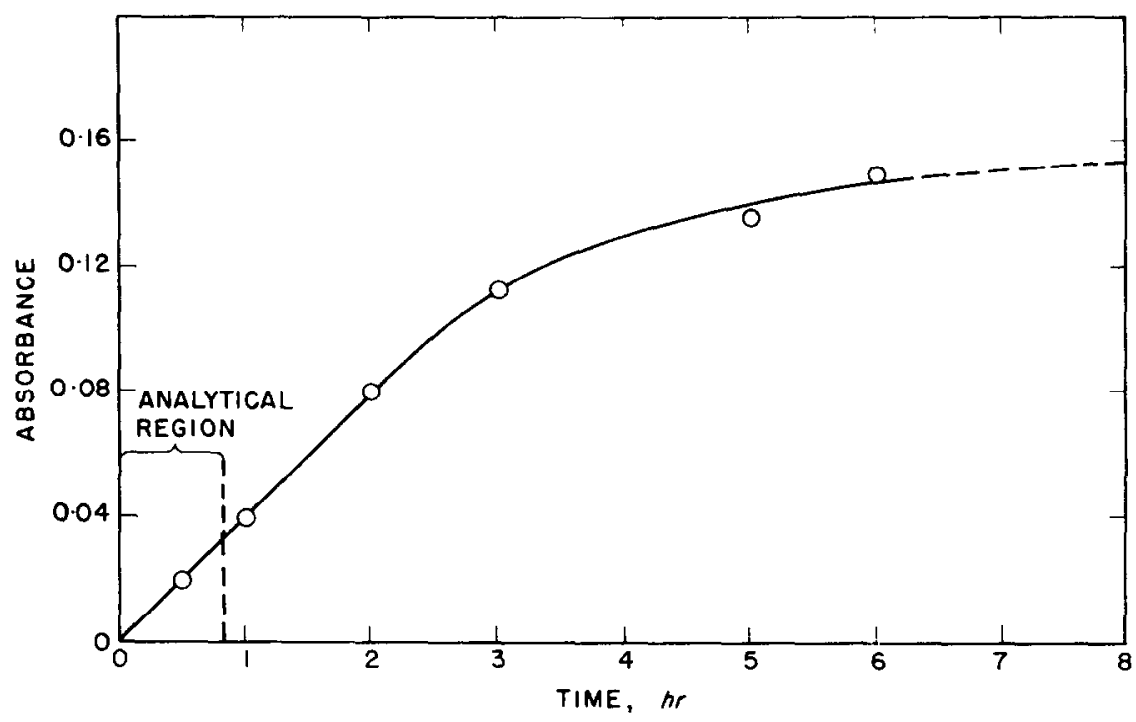

FIG. 3.-The rate curve for the reaction of $0.5 \times 10^{-4} \mathrm{M}$ fructose and $0.94 \times 10^{-8} \mathrm{M}$ $\mathrm{THTCl}$ at $25^{\circ} \pm 0.05^{\circ}$.

the absolute sensitivity of method is about $10 \%$ of what could be realised by using a method which allows the reaction to go to completion. However, it is felt that the time saved, the simplicity of the calculations, and the increase in precision obtained by using this initial portion of the reaction, more than compensate for the loss of sensitivity.

At present, the explanation of the "pseudo zero-order" behaviour (linearity of the extent of reaction with time) during the initial $20 \%$ of the reaction is not known. The mechanism of the reaction must be considerably more complex than might be expected.

The value of the different proportionality constants, $K$, at $t=20 \mathrm{~min}$ and $t^{\prime}=50$ min.* for the seven sugars studied are given in Table I. Also listed in Table I are the relative rates of reaction of these sugars using glucose as the basis of comparison. It was found experimentally that for mixtures whose ratio of rates (rate of faster reacting component: rate of slower reacting component in equal concentrations) was $2: 1$ or less, unsatisfactory results were obtained. Thus it appears that the

* These times were arbitrarily chosen in this study; 20 min for $t$ was convenient because sufficient colour was usually developed at this time to give an accurate and precise absorbance measurement; and 50 min for $t^{\prime}$ ensured that the optical density was not too great to obtain a reading. 
Table I.-The Relative rate CONSTANTS fOR the Reaction of sugars With 2,3,5-TRIPHENYL-2H-TETRAZOLIUM CHLORIDE

Concentration of sugar $=1.0 \times 10^{-3} \mathrm{M}$

concentration of THTCl $=0.95 \times 10^{-8} \mathrm{M}$;

concentrations of $\mathrm{NaOH}=0.31 \mathrm{M}$. Temperature $=25^{\circ}+0.05^{\circ}$

\begin{tabular}{lccc}
\hline \multirow{2}{*}{ Compound } & \multicolumn{2}{c}{ Proportionality constants } & Relative rate \\
\cline { 2 - 3 } & $K_{t}(20 \mathrm{~min})$ & $K_{t}(50 \mathrm{~min})$ & \\
\hline Fructose & 0.68 & 1.70 & 5.3 \\
Sorbose & 0.52 & 1.28 & 4.0 \\
Glucose & 0.13 & 0.32 & 1 \\
Galactose & 0.090 & 0.23 & 0.72 \\
Mannose & 0.029 & 0.070 & 0.22 \\
Xylose & 0.12 & 0.30 & 0.94 \\
Ribose & 0.091 & 0.23 & 0.73 \\
Creatinine & - & - & No reaction \\
Glutathione & - & - & No reaction \\
Ascorbic acid & - & 131 \\
\hline
\end{tabular}

experimental errors in measuring the various parameters, $P_{t}, P_{t}, t, t^{\prime}$, and the values of $K$ in this method are sufficiently large to introduce significant errors in the determination when the ratio of rate constants is small. A similar restriction on low ratios of rate constants was also observed for the first-order "method of proportional equations." 16,17 THTCl is not suitable for the differential rate of determination of fructose-sorbose, glucose-galactose, glucose-xylose, glucose-ribose or xylose-ribose mixtures. It is, however, quite suitable for analytical determinations of all the other binary combinations of the sugars. A few specimen results are given in Table II.

TABLE II.-The aNALYSIS OF SOME SUGAR MIXTURES

\begin{tabular}{|c|c|c|c|c|c|}
\hline & \multirow{2}{*}{ Mixture } & \multicolumn{2}{|c|}{$[\mathrm{A}], M \times 10^{3}$} & \multicolumn{2}{|c|}{$[\mathrm{B}], M \times 10^{3}$} \\
\hline & & Present & Found & Present & Found \\
\hline \multirow[t]{6}{*}{1.} & & 0.33 & 0.33 & 3.0 & 2.6 \\
\hline & & 0.55 & 0.44 & 2.8 & 3.2 \\
\hline & A. Fructose & 1.3 & 1.3 & 2.0 & 2.3 \\
\hline & B. Glucose & 1.65 & 1.7 & 1.65 & 1.8 \\
\hline & & 2.2 & 2.3 & 1.1 & 1.2 \\
\hline & & 2.5 & 2.3 & 0.83 & 1.1 \\
\hline \multirow[t]{2}{*}{2.} & A. Fructose & 1.65 & 1.7 & 1.65 & 1.6 \\
\hline & B. Galactose & 2.2 & 2.2 & 1.1 & 0.83 \\
\hline \multirow[t]{2}{*}{3.} & A. Fructose & 1.65 & 1.7 & 1.65 & 1.6 \\
\hline & B. Ribose & 1.0 & 1.0 & 2.3 & 2.3 \\
\hline 4. & $\begin{array}{l}\text { A. Glucose } \\
\text { B. Mannose }\end{array}$ & 1.0 & 0.8 & 2.3 & 2.1 \\
\hline \multirow[t]{3}{*}{5.} & A. Sorbose & 0.83 & 0.8 & 2.5 & 2.8 \\
\hline & B. Glucose & 1.65 & 1.7 & 1.65 & 1.8 \\
\hline & & 2.5 & 2.7 & 0.83 & 0.7 \\
\hline
\end{tabular}

A relative error of $\sim 3.4 \%$ was obtained for approximately 50 binary sugar mixtures analysed.

The compounds ascorbic acid, creatinine and glutathione occur in blood serum in varying amounts, and interfere with all the analytical methods of sugar determinations in blood serum utilising their reducing ability. 78,19 The analysis of mixtures of sugar in blood serum is of interest, ${ }^{20}$ and a differential rate technique has been successfully employed for the analysis of fructose-glucose mixtures in blood serum (but is subject to error when the above compounds are present in concentrations 
greater than $4 \%$ ). ${ }^{7}$ It was therefore decided to measure the rates of reaction of these species to see if they would also interfere with the method presented here. It was found that creatinine and glutathione did not react to any detectable extent after $1 \mathrm{hr}$ and do not, therefore, interfere with the determination of the sugar mixtures. Ascorbic acid, however, reacted with the THTCl very rapidly, as shown in Table I, and as little as $2 \%$ of ascorbic acid in a sugar mixture would result in appreciable error in a determination.

The red formazan product of the reaction is reasonably stable, but does undergo some decomposition with time. When dissolved on the addition of the acid-pyridine solution (which stops the reaction), the absorbance of the resulting solutions decreased by about $4 \%$ in a 4 -hr period.

Acknowledgment-Acknowledgment is made to the Petroleum Research Fund (PRF), administered by the American Chemical Society, and of a grant from the Horace H. Rackman School of Graduate Studies of the University of Michigan for partial support of this research. Two of the authors (L. M. B. and D. P.) are indebted to the National Science Foundation for Undergraduate Summer Research Fellowships.

Zusammenfassung-Die Reaktionsgeschwindigkeiten von 2,3,5-Triphenyl-2H-tetrazoliumchlorid mit den häufigeren Hexosen Glucose, Fructose, Mannose, Sorbose, Galactose und den Pentosen Xylose und Ribose wurden gemessen. Unter bestimmten Bedingungen wurde in einem gewissen Bereich des Umsatzes gefunden, daß der Umsatz der Reaktionszeit direkt proportional war (Reaktion "pseudonullter" Ordnung). Außerdem waren die Reaktionsgeschwindigkeiten dieser Zucker meistens stark verschieden. Demnach erwies sich dieses Reagens als sehr zufriedenstellend, um binäre Mischungen der meisten geprüften Zucker mit der in dieser Arbeit entwickelten Methode des Geschwindigkeitsunterschiedes bei Konkurrenzreaktionen "nullter" Ordnung zu analysieren. Mehrere Bestimmungsbeispiele werden angegeben. Die Reaktionsgeschwindigkeiten von 2,3,5-Triphenyl-2 $\boldsymbol{H}$-tetrazoliumchlorid mit Ascorbinsäure, Kreatinin und Glutathion, Verbindungen, die häufig im Blutserum vorkommen und die meisten Zuckeranalysen im Blutscrum stören, wurden ebenso gemessen, um festzustellen, ob sie auch hier stören würden. Glutathion und Kreatinin reagieren nicht und stören bei den Zuckeranalysen nicht. Ascorbinsäure dagegen reagiert schnell und führt schon in einer Menge von 1-2\% zu falschen Zuckerwerten.

Résumé - On a étudié les vitesses de réaction du chlorure de 2,3,5triphényl-2H-tétrazolium avec les hexoses et pentoses les plus courants: glucose, fructose, mannose, sorbose et galactose, xylose et ribose. On a trouvé que, dans certaines conditions limitées le rendement atteint par la réaction est directement proportionnel à la durée de celle-ci (réaction d'ordre "pseudo-zéro"). Les vitesses de réaction de ces sucres sont également très différentes dans la plupart des cas. Ainsi, le comportement de ce réactif est tout à fait satisfaisant pour le dosage de mélanges binaires de la plupart des sucres essayés, par la technique simple de vitesse différentielle développée dans ce mémoire pour des réactions concurrentes d'ordre zéro. Quelques dosages sont donnés à titre d'exemples. On a aussi étudié les vitesses de réaction du chlorure de 2,3,5 triphényl-2H-tétrazolium avec les composés suivants: acide ascorbique, créatinine et glutathion, que l'on trouve souvent dans le sérum sanguin et quj interfèrent dans la plupart des méthodes d'analyse du sucre du sérum sanguin; ceci afin de voir si ces composés interfèrent dans le dosage effectué selon la méthode décrite dans ce mémoire. On a trouvé que le glutathion et la créatinine ne réagissent pas le avec réactif et n'interfêrent pas dans l'analyse de mélanges de sucres. L'acide ascorbique, cependant, réagit rapidement, et une quantité de $1-2 \%$ seulement conduit à une erreur dans le dosage du mélange de sucres. 


\section{REFERENCES}

${ }^{1}$ L. Hough in Methods of Biochemical Analysis, edited by J. D. Glick. Interscience Publishers, Inc., 1956, p. 205.

2 C. T. Bishop and F. P. Cooper, Canad. J. Chem., 1960, 38, 388.

${ }^{3}$ H. W. Kircher, Analyt. Chem., 1960, 32, 1103.

A. G. McInnes, D. H. Ball, F. P. Cooper and C. T. Bishop, J. Chromatog., 1958, 1, 556.

${ }^{5}$ S. Siggia, J. G. Hanna and N. M. Serencha, Analyt. Chem., 1964, 36, 638.

' S. L. Bonting, Arch. Biochem. Biophysics, 1954, 52, 272.

' L. J. Papa, H. B. Mark, Jr. and C. W. Reilley, Analyt. Chem., 1962, 34, 1443.

${ }^{8}$ A. M. Mattson, C. O. Jenson and R. A. Dutcher, Science, 1947, 106, 294.

$\because$ R. Kuhn and D. Jerchel, Ber., 1941, 74 B, 949.

${ }^{10}$ L. F. Fieser and M. Fieser, Topics in Organic Chemistry. Reinhold Publishing Corp., 1963, p. 77.

11 A. M. Mattson and C. O. Jensen, Analyt. Chem., 1950, 34, 182.

${ }^{12}$ R. G. Garmon and C. W. Reilley, ibid., 1962, 34, 600.

${ }^{13}$ H. B. Mark, Jr., ibid., 1964, 36, 1668.

14 S. Siggia and J. G. Hanna, ibid., 1961, 33, 896.

${ }^{15}$ C. W. Reilley and L. J. Papa, ibid., 1962, 34, 801.

${ }^{16}$ H. B. Mark, Jr., L. J. Papa and C. W. Reilley in Advances in Analytical Chemistry and Instrumentation, Vol. II, edited by C. W. Reilley. Interscience Publishers, Inc., New York, 1963, p. 255.

${ }^{17}$ L. J. Papa, H. B. Mark, Jr. and C. W. Reilley, to be published.

${ }^{18}$ J. B. Hill and G. Kessler, J. Lab. Clin. Med., 1961, 57, 970.

${ }_{10}$ M. Somogyi, J. Biol. Chem., 1928, 80, 733; 1937, 83, 137; 1945, 160, 69.

${ }^{20}$ L. D. Scott, Biochem. J., 1938, 29, 1012. 